SYPHILIS

\title{
Declining syphilis prevalence among pregnant women in northern Botswana: an encouraging sign for the HIV epidemic?
}

\author{
T L Creek, H Thuku, B Kolou, M Rahman, P H Kilmarx
}

Sex Transm Infect 2005;81:453-455. doi: 10.1136/sti.2004.014068

See end of article for authors' affiliations

......................

Correspondence to: Tracy Creek, Centers for Disease Control and Prevention, Global AIDS Program, Mailstop E-04, Atlanta, GA 30333, USA; tgc0@cdc.gov

Accepted for publication 30 March 2005 prevalence among antenatal women in a high HIV prevalence

Objectives: To evaluate trends in syphilis prevalence among antenatal women in a high HIV prevalence
setting in northern Botswana. Methods: Laboratory logbooks of antenatal syphilis testing for 1992-2003 in Francistown, Botswana's second largest city, were reviewed, and a consecutive sample of 750 women per year from 1992-2003 were analysed. VDRL result and age were recorded. A positive result was considered a case.

Results: Overall syphilis prevalence (VDRL positive) among pregnant women in Francistown decreased from $12.4 \%$ in 1992 to $4.3 \%$ in 2003 ( $p \leqslant 0.001)$. The downward trend in overall syphilis prevalence began in 1997. There was no change in syphilis prevalence from 1992-6. Beginning in 1997, there has been a significant decrease in syphilis prevalence in all age groups.

Conclusions: Syphilis in pregnant women in Francistown has been decreasing for the last 6 years, despite extremely high HIV prevalence (stable at $\geqslant 40 \%$ since 1996) in the same population. Reasons contributing to the decline in syphilis rates may include nationwide implementation of syndromic management of sexually transmitted diseases (STDs) in 1992, improved access to health care, and less risky sexual behaviour. There is evidence from other sources indicating that risky sexual behaviour in Botswana has decreased during the HIV epidemic.
$\mathrm{H}$ istorically, Botswana's antenatal syphilis prevalence has been high, reflecting a generally high prevalence in southern Africa. ${ }^{1-8}$ Since the early 1990s, Botswana has had a very high HIV prevalence. ${ }^{9}$ In 2003, prevalence among antenatal women was $37.4 \% .^{9}$ No significant decline in national HIV prevalence has been seen to date. Monitoring trends in syphilis prevalence among antenatal women may predict future trends in the HIV epidemic, as HIV trends may follow trends of other sexually transmitted diseases (STD)..$^{10}$

The objective of this study was to analyse trends in syphilis prevalence among antenatal women in a very high HIV prevalence setting in northern Botswana, and relate these data to data on other STDs, HIV prevalence, and sexual behaviour in Botswana.

\section{METHODS}

Laboratory logbooks of antenatal syphilis testing for 19922003 in Francistown, Botswana's second largest city, were reviewed. Francistown is a city of 83000 people. ${ }^{11}$ Approximately 3500 deliveries per year occur in Francistown healthcare facilities, and more than 95\% of pregnant women have at least one visit for antenatal care. ${ }^{12}$ All syphilis testing in public antenatal clinics is performed at a single laboratory. A consecutive sample of 750 women per year, beginning in June, from 1992-2003 were analysed using $\chi^{2}$ for trend after data were entered into Epi-Info 6. Venereal Disease Research Laboratory reaction (VDRL) result and age were recorded. A positive VDRL result was considered a case.

\section{RESULTS}

Overall syphilis prevalence among pregnant women in Francistown decreased from $12.4 \%$ in 1992 to $4.3 \%$ in 2003 $(p \leqslant 0.001)$ (fig 1$)$. The downward trend began in 1997. There was no change in syphilis prevalence between 1992 and 1996. Since 1997, there has been a significant decrease in syphilis prevalence in each of the 15-19 $(\mathrm{p}=0.02), 20-24$

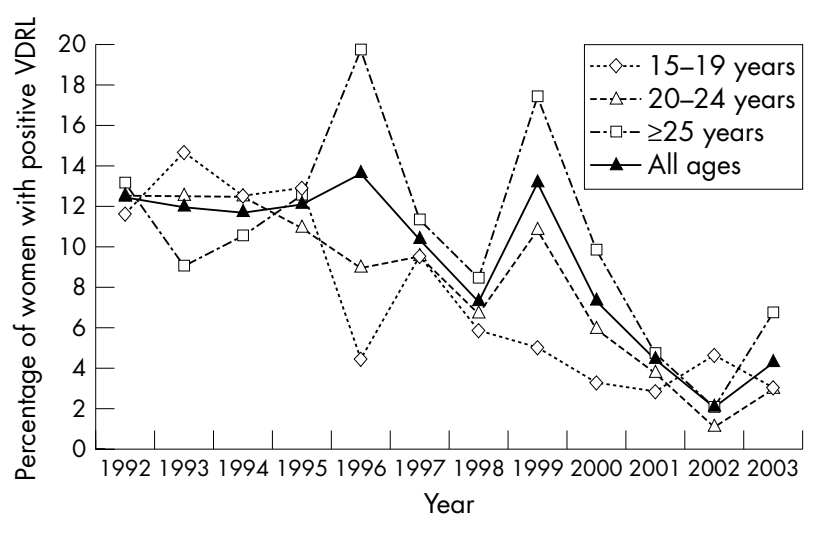

Figure 1 Syphilis prevalence in pregnant women by age group, Francistown, Botswana 1992-2003.

$(p=<0.0001)$, and $>25 \quad(p=<0.0001)$ age groups. The decrease in overall prevalence was not accounted for by differences in the percentage of antenatal women in each age group.

\section{DISCUSSION}

Trends in syphilis, other STDs, and HIV

Published antenatal prevalence of active syphilis (defined as positive rapid plasma regain test (RPR) with and without confirmatory testing) in southern Africa over the last 20 years has ranged from $6.5-14 \% .{ }^{1-4}$ Prevalence of active or previous syphilis (defined as positive treponemal test) has ranged from $8.0-41 \% .^{5-8}$ Francistown's syphilis prevalence

Abbreviations: BAIS, Botswana AIDS Impact Survey; RPR, rapid plasma regain test; STD, sexually transmitted diseases; VDRL, Venereal Disease Research Laboratory reaction 


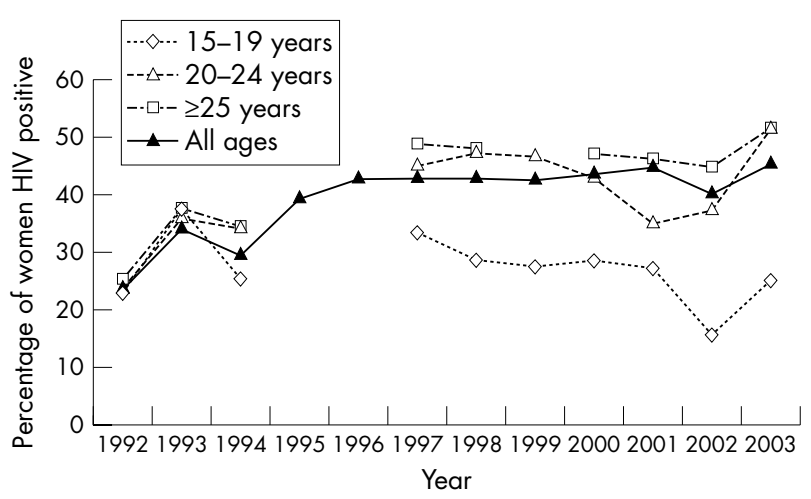

Figure 2 HIV prevalence in pregnant women by age group, Francistown, Botswana 1992-2003.

may be overestimated by the use of VDRL alone (no confirmatory testing or titres are performed); however, as there was no change in laboratory methodology during 19922003, trends should be accurately reflected. The sharp decline seen here represents a substantial change from baseline syphilis prevalence before and in the early years of southern Africa's HIV epidemic. The earliest syphilis prevalence data published from Botswana are from a survey of 113 antenatal women in Maun, northern Botswana, in 1990, which showed that $17 \%$ of women had active syphilis, defined as two out of three positive non-treponemal tests (VDRL, RPR, VDRLELISA), and two out of three positive treponemal tests (TPHA, FTA-Abs, Flagellum-ELISA). ${ }^{8}$ In that survey $41 \%$ of women had either active or previous syphilis (previous syphilis defined as two out of three negative non-treponemal tests and two out of three positive treponemal tests).

Prevalence of three major STDs in a slightly different population (women attending family planning clinics) in Botswana has also declined significantly in recent years, with rates of active syphilis (defined here as a positive RPR confirmed by either FTA-Abs or TPHA) declining from 18\% to $2 \%$ from 1993-2002, gonorrhoea declining from $7 \%$ to $3 \%$, and trichomoniasis declining from $17 \%$ to $7 \%$ during this time. ${ }^{13-15}$

Botswana's first national surveillance for HIV was done in 1992 and it found that HIV prevalence among pregnant women was $18 \%{ }^{9}$ Since that time HIV has devastated this country of 1.7 million people with no significant decrease in national prevalence seen to date. From 1992-6, when there was no change in syphilis prevalence, HIV prevalence in Francistown's antenatal population increased from $23.7 \%$ to $43.1 \%{ }^{9}$ (fig 2). Since 1997, when syphilis began to decline, overall HIV prevalence in Francistown has remained stable at $40 \%-46 \%(\mathrm{p}=0.5)$, although there has been a decrease in HIV prevalence in the $15-19(\mathrm{p}<0.01)$ age group. ${ }^{9}$ Trends in the youngest pregnant women may predict future trends in the overall population, as HIV infections in 15-19 year olds are likely to be recent and best reflect incidence of infection. ${ }^{16}$

\section{Possible reasons for decline in syphilis and STD prevalence}

Syndromic management of STDs was implemented in Botswana in 1992, ${ }^{13}$ and widespread use of antibiotics and good access to health care overall may have contributed to the decline in syphilis and STD prevalence. However, in the 4 years following the introduction of syndromic management of STDs, there was no change in the prevalence of syphilis in Francistown. Furthermore, the youngest pregnant women, who are likely to have had fewer opportunities for diagnosis of an asymptomatic infection (during a previous pregnancy or family planning visit, for example), have shown significant decreases in syphilis prevalence.

Public health interventions implemented to control the HIV epidemic have included information campaigns on billboards, television, and radio; condom social marketing and free distribution; the establishment of free standing, anonymous voluntary HIV counselling and testing centres (the first of which opened in 2000), and the establishment of Africa's first national programmes providing prevention of mother to child transmission of HIV services (2001) and antiretroviral therapy (2002) in the public health sector. After a decade of dissemination of these messages, there are indications that many Batswana, especially in the younger age groups, are practising less risky sex. This may have a role in the decrease in syphilis reported here, and the decrease in other STDs seen in family planning clinics.

\section{Evidence of behaviour change}

Botswana's 1988 family health survey, a population based survey of 4200 women, reported that $7.3 \%$ of girls had had sex by age 15, and that the median age at first intercourse was $17 .{ }^{17}$ The Botswana AIDS Impact Survey (BAIS), a population based survey of 4267 people aged 15-49 done in 2001, revealed that of 15 year old respondents, only 3\% of boys and $2.3 \%$ of girls reported ever having had sex, and that median age at first intercourse was 19 for both sexes. ${ }^{18}$

The BAIS report also indicates that the number of sexual partners per person in Botswana in 2001 was low, with $89 \%$ of sexually active women and $75 \%$ of sexually active men reporting only one partner in the past year. Only 5\% of men and $1 \%$ of women reported sex with three or more partners in the past year. Condom use is high, with $89 \%$ of men and $75 \%$ of women reporting using a condom at the last sex act with a non-marital, non-cohabiting partner, and 38\% of people using a condom at last sex act with a marital or cohabiting partner.

Teenage pregnancy rates have decreased over the last 10 years. The percentage of girls aged 15-19 who gave birth in Botswana in 1992 was $8.2 \%$, compared to $5.6 \%$ in 2001 $(\mathrm{p}<0.0001) . .^{17} 18$

Condom distribution over the last several years has increased substantially. Sales of Botswana's most popular condom brand, Lover's Plus, increased from one million condoms in 1993 to just over three million condoms in 2001 (J Heichelheim, Population Services International, 2003, personal communication). Free condom distribution through the Ministry of Health has increased rapidly as well, from 1.3 million condoms in 1998 to 21.4 million in 2002 (A Kgosiemang, Botswana Ministry of Health Central Medical Stores, 2003, personal communication).

\section{Conclusions}

Declines in risky sexual behaviour in a population may be reflected relatively quickly in decreased prevalence of curable bacterial STDs such as syphilis; a decline in prevalence of incurable viral infections, such as HIV, may only be seen after a longer time period. Though there are intrinsic limitations in discussing STD prevalence among sexually active women only, as they may not represent all populations, trends in this group are useful for estimating national disease trends. The substantial decline in the prevalence of syphilis and other STDs among women in antenatal and family planning clinics; declining prevalence of HIV infection in young pregnant women in Francistown; and evidence of safer sexual behaviour from multiple sources may all point towards a decrease in sexual transmission of HIV in Botswana. This may become apparent in future rounds of Botswana's annual sentinel serosurveillance. 


\section{ACKNOWLEDGEMENTS}

The authors thank the following people: Dr Kereng Masupu (National AIDS Coordinating Agency and the Ministry of Health AIDS/STD Unit) and Dr Thierry Roels (BOTUSA Project) for surveillance data used in the preparation of this manuscript; and Phil Hastings (Centers for Disease Control and Prevention) for statistical review.

\section{CONTRIBUTORS}

TC located, collected and analysed the data, and wrote the manuscript; HT provided syphilis data for the manuscript; BK provided laboratory information for the manuscript; MR contributed to the manuscript; PHK conceived of the study, suggested ways to explore sexual behaviour trends, and contributed substantially to writing the manuscript.

\section{Authors' affiliations}

T L Creek, P H Kilmarx, Global AIDS Program, Centers for Disease Control and Prevention, Atlanta, GA, USA

T L Creek, Epidemiology Program Office, Centers for Disease Control and Prevention, Atlanta, GA, USA

H Thuku, B Kolou, Francistown District Health Team, Francistown, Botswana

M Rahman, Ministry of Health AIDS/STD Unit, Gaborone, Botswana P H Kilmarx, Centers for Disease Control and Prevention BOTUSA Project, Gaborone, Botswana

Support received: This study was carried out with the financial support of the US Centers for Disease Control and Prevention as part of a collaboration with the Government of Botswana.

Conflicts of interest: none.

Ethical approval: This activity was not human subjects research.

\section{REFERENCES}

1 Ratnam AV, Din SN, Hira SK, et al. Syphilis in pregnant women in Zambia. $\mathrm{Br} J$ Vener Dis 1982:58:355-8.
2 Dietrich M, Hoosen AA, Moodley J, et al. Urogenital tract infections in pregnancy at King Edward VIII Hospital, Durban, South Africa. Genitourin Med 1992;68:39-41

3 Wilkinson D, Sach M, Connolly C. Epidemiology of syphilis in pregnancy in rural South Africa: opportunities for control. Trop Med Int Health 1997;2:57-62.

4 Rotchford K, Lombard C, Zuma K. Impact on perinatal mortality of missed opportunities to treat maternal syphilis in rural South Africa: baseline results from a clinic randomized controlled trial. Trop Med Int Health 2000;5:800-4.

5 Hira SK, Bhat GJ, Chikamata DM, et al. Syphilis intervention in pregnancy: Zambian demonstration project. Genitourin Med 1990;66:159-64.

6 O'Farrell N, Hoosen AA, Kharsany ABM, et al. Sexually transmitted pathogens in pregnant women in a rural South African community. Genitourin Med 1989;65:276-80.

7 Sturm AW, Wilkinson D, Ndovela N, et al. Pregnant women as a reservoir of undetected sexually transmitted diseases in rural South Africa: implications for disease control. Am J Public Health 1998;88:1243-5.

8 Sheller JP, Pedersen NS, Kvinesdal BB, et al. HIV infection, syphilis and genital diseases in Maun, Botswana. Ugeskrift for Laeger 1990;152:1441-3.

9 Botswana National AIDS Coordinating Agency (NACA). 2003 Second Generation HIV/AIDS Surveillance Technical Report. Gaborone: NACA, 2003.

10 Hanenberg RS, Rojanapithayakorn W, Kunasol P, et al. Impact of Thailand's HIV-control programme as indicated by the decline of sexually transmitted diseases. Lancet 1994;344:243-5.

11 Government of Botswana Central Statistics Office. 1991 \& 2001 Population and housing census. Gaborone: Central Statistics Office, 1992 and 2001.

12 Government of Botswana Central Statistics Office. 1992-2002 Health statistics reports. Gaborone: Central Statistics Office.

13 Moffat H, Rahman M, Ballard R, et al. Aetiology of STDs in family planning, ANC and STD clinics. Gaborone: Botswana Ministry of Health and South African Institute of Medical Research, 1993.

14 Rahman M, Ramolen M, Sundby J, et al. National survey on aetiology and drug resistance patterns of STIs among family planning, ANC, and STD clinic clients. Gaborone: National AIDS/STD Unit, 1997.

15 Paz-Bailey G, Ryan C, Rahman M. Sexually transmitted infections in Botswana: prevalence of infection and evaluation of syndromic management algorithms. Gaborone: National AIDS/STD Unit, February, 2002.

16 Podgor M, Leske C. Estimating incidence from age-specific prevalence for irreversible diseases with differential mortality. Stat Med 1986:5:573-8.

17 Government of Botswana Central Statistics Office. 1988 Family Health Survey. Gaborone: Central Statistics Office, 1989.

18 Government of Botswana Central Statistics Office and Family Health International. Botswana AIDS Impact Survey (BAIS). Gaborone: Family Health International, 2001.

\section{bmjupdates+}

bmjupdates+ is a unique and free alerting service, designed to keep you up to date with the medical literature that is truly important to your practice. bmjupdates+ will alert you to important new research and will provide you with the best new evidence concerning important advances in health care, tailored to your medical interests and time demands.

\section{Where does the information come from?}

bmiupdates+ applies an expert critical appraisal filter to over 100 top medical journals A panel of over 2000 physicians find the few 'must read' studies for each area of clinical interest

Sign up to receive your tailored email alerts, searching access and more...

www.bmjupdates.com 